\title{
Editorial
}

\section{Os resultados científicos e o acesso pela sociedade}

\author{
Scientific findings and their access by the society
}

\section{Thalissa Ferreira}

Ciência é conhecimento público - John Ziman ${ }^{1}$; o resultado da produção científica não é patente do autor, mas pertence a sociedade como um todo, a qual visa, primordialmente, beneficiar. Apesar disso, é perceptível a distância entre os achados advindos da produção científica e a parte dos indivíduos não envolvida diretamente nesse processo.

A comunicação é fundamental para a ciência; por meio dela os resultados são divulgados, discutidos, complementados, revistos e, muitas vezes, usados como inspiração para novas linhas de pesquisas, incrementando cada vez mais o avanço. A internet é, inequivocamente, o instrumento mais facilitador desse processo, permitindo tanto a difusão de trabalhos em larga escala, como a interação entre autores.

Além disso, o ambiente virtual, com todas as suas peculiaridade, admite que cada usuário exerça o papel de autor, leitor ou avaliador, dependendo de seus interesses no momento. Temos, atualmente, plataformas de busca e socialização repletas de informações de autores conhecidos, desconhecidos e alguns anônimos, todos buscando a visibilidade de suas divulgações, que cumprem os mais diversos objetivos.

Se por um lado, essa dinâmica permite maior facilidade de divulgação de trabalhos e de grandes pesquisas, por outro, provavelmente dificulta cada vez mais a aproximação entre a população e os resultados científicos, tanto porque estes têm que competir pela visibilidade em meio a tantos conteúdos que são produzidos e depositados na rede diariamente, como porque os métodos de busca estão sujeitos a vieses de relevância e estão limitados a subjetividade do internauta no momento da expressão das palavras-chaves de sua pesquisa.

Acadêmica de Medicina, Faculdade de Medicina FMUSP, Universidade de São Paulo. Diretora de Marketing e Tesoureira da Revista de Medicina - Gestão 2019. ORCID: https://orcid.org/0000-0003-2601-3603. Email: thalissa.f@fm.usp.br. 
Ferreira T. Os resultados científicos e o acesso pela sociedade.

Talvez, a distinção do conteúdo científico possa ser conseguida por meio da qualidade da informação; a veracidade da fonte pode destacar conteúdos em detrimentos de outros. Porém, como desenvolver um mecanismo eficiente de direcionamento de busca aos resultados científicos ainda é um desafio a ser enfrentado de forma que a ciência seja, na prática, discutida e analisada não somente por seus autores, mas também por seus maiores beneficiados.

\section{Referência}

Droescher FD, Silva EL. Researchers and scientific production. Perspect Ciên Inf. 2014;19(1):170-89. http://dx.doi.org/10.1590/S1413-99362014000100011 